\title{
Comparison of Tautomerization, Vibrational Spectra and UV-Vis Analysis of $\beta$-Ketoester With Acetylacetone. An Experimental and Theoretical Study
}

\section{Mozhgan Mahmoudi Aval}

Ferdowsi University of Mashhad Faculty of Sciences

Ali Nakhaei Pour ( $\square$ a.nakhaei@um.ac.ir)

Ferdowsi University of Mashhad Faculty of Sciences https://orcid.org/0000-0002-8137-499X

Mohammad Vakili

Ferdowsi University of Mashhad Faculty of Sciences

Ali Mohammadi

Ferdowsi University of Mashhad Faculty of Sciences

\section{Research Article}

Keywords: AIM, DFT, $\beta$-ketoester, NBO, Tautomerization

Posted Date: May 4th, 2021

DOl: https://doi.org/10.21203/rs.3.rs-455123/v1

License: (c) (1) This work is licensed under a Creative Commons Attribution 4.0 International License.

Read Full License 


\title{
Comparison of tautomerization, vibrational spectra and UV-Vis analysis of $\square$-ketoester
} with acetylacetone. An experimental and theoretical study

\author{
Mozhgan Mahmoudi Aval, Ali Nakhaeipour ${ }^{1}$, Mohammad Vakili, Ali Mohammadi \\ Department of Chemistry, Faculty of Science, Ferdowsi University of Mashhad, Mashhad, Iran.
}

\begin{abstract}
In this study, the equilibrium constants, keto-enol ratio, and hydrogen bond strength among keto and cis-enol forms of acetylacetone (AA), methyl acetoacetate (MAA), ethyl acetoacetate (EAA), ethyl 2-methyl acetoacetate (EMA), benzyl acetoacetate (BAA), and ethyl benzoyl acetone (EBA) have been investigated using density functional theory (DFT), compared with the experimental results. According to the obtained results, the relative energy of cis-enol and keto forms of $\beta$-ketoesters in gas phases is greater than that of acetylacetone, so the enol form of acetylacetone is more stable and it causes to increase its strength of intramolecular hydrogen bond. The electronic properties of these compounds were surveyed by NMR, FT-IR, and UV-Vis spectra. Besides, the obtained outcomes showed that the keto forms of $\beta$-ketoesters in the presence of acetonitrile and carbon tetrachloride as a solvent have a high absorption coefficient due to the polarity of the solvent.
\end{abstract}

Keywords: AIM, DFT, $\beta$-ketoester, NBO, Tautomerization.

${ }^{1}$ Corresponding author: Email: a.nakhaei@um.ac.ir, nakhaeipoura@yahoo.com, Tel: $+985138805539$ 


\section{Declarations}

\section{Conflicts of interest}

There are no Conflicts of interest to declare.

\section{Funding}

Funding for this work has been received from the Ferdowsi University of Mashhad, Mashhad, Iran (grant No. 45820).

\section{Availability of data and materials}

All data generated or analyzed during this study are included in this published article

\section{Data availability}

Not applicable

\section{Code availability}

Not applicable

\section{Authors' contributions}

Mozhgan Mahmoudi Aval: Writing-Original Draft, Methodology, Formal analysis

Dr. Ali Nakhaei Pour*: Supervision, Software, Funding acquisition, Writing and Editing

Dr.Mohammad Vakili: Supervision, Writing and Editing, Responsible for IR, Raman and UV spectra

Dr. Ali Mohammadi: checked the manuscript English level and quality of the results. 


\section{Introduction}

$\beta$-Dicarbonyl compounds included $\beta$-diketones and $\beta$-ketoesters have various keto and enol forms. The phenomenon of keto-enol equilibrium is called "Tautomerism" and the forms are known as tautomers. The keto-enol equilibrium depends on the electric features of the substituents, temperature, and the environment of the solvent. Under usual conditions when one tautomer is more stable than the others, it is known as the "stable form". An intramolecular hydrogen bond is present in closed cis-enol forms of $\beta$-dicarbonyl and it leads to a stable form of the tautomer [1-2].

In the structure of $\beta$-ketoesters, the presence of the alkoxy group decreases the enol content and results in the reduction of intramolecular hydrogen bond strength [3-6]. Furthermore, the intramolecular hydrogen bond (IHB) in $\beta$-ketoesters is weaker than the $\beta$-diketones. According to theoretical and experimental data from several literature, the electron-donating and electron-withdrawing groups which are present in the $\alpha$ - and $\beta$-position of $\beta$-dicarbonyl, influence the intramolecular hydrogen bond strength [7-9]. Bunkoeda et.al established the transparent sol-gels with captured sensitive and selective substances for the detection of formaldehyde [10]. They investigated the sensitivity of the reactions of acetylacetone and methyl acetoacetate with formaldehyde. The results showed that acetylacetone reacted faster with formaldehyde than methyl acetoacetate. Fokendt et.al, using ${ }^{1} \mathrm{H}$ NMR spectroscopy, investigated the intermolecular tautomeric interaction of keto-enol $\beta$-dicarbonyl compounds [11]. They found that the proton chemical shift of enol form in acetylacetone (AA), methyl acetoacetate (MAA) and, ethyl acetoacetate (EAA) in the pure liquid phase, is 14.6, 11.96, $11.6 \mathrm{ppm}$, and in the gas phase, is 15.2, 11.97, $12.01 \mathrm{ppm}$, respectively. According to the above studies, a definite explanation of the chemical reactivity is not easy without having qualitative and quantitative information about tautomers [12]. 
The present study aims to investigate the hydrogen bond strength and thermodynamic and geometry parameters of some $\beta$-ketoesters such as "MAA, EAA, EMA" and comparing them with AA, benzylacetoacetate (BAA), and ethyl benzoylacetate (EBA) in the gas and solution phase. All theoretical results such as density functional theory (DFT), atoms-in-molecules (AIM), and natural bond orbital (NBO), compared with experimental methods included ${ }^{1} \mathrm{H}-$ NMR, FT-IR, and UV-Vis spectroscopy.

\section{Keto-enol equilibrium of acetylacetone and $\beta$-ketoesters compounds}

Acetylacetone (AA), $\left(\mathrm{R}_{1}=\mathrm{R}_{3}=\mathrm{CH}_{3}, \mathrm{R}_{2}=\mathrm{H}\right.$, without $\mathrm{OR}_{3}$ group) usually exists in both keto and enol forms. According to NMR studies, the enol tautomer prevails from $76 \%$ in ethanol [13] to $83 \%$ in $\mathrm{CDCl}_{3}$ solution and $55 \%$ in DMSO solution at $40^{\circ} \mathrm{C}$ [14] and $74 \%$ in neat and $90 \%$ in $\mathrm{CCl}_{4}$ solution at $37^{\circ} \mathrm{C}$ [15]. Based on equilibrium constants for tautomerization of acetylacetone in various solvents at 0.1 mole fraction of solute, and the enol ratio at $33^{\circ} \mathrm{C}$ are $24-96 \%$ in carbon tetrachloride, $6.7-87 \%$ in chloroform, 3.4-77\% in Ethanol, $2.8-74 \%$ in methanol, 1.6-62\% in acetonitrile and DMSO [16]. According to these results, the enol content decreases in polar solvents (acetonitrile and DMSO). Cook and Feltman determined the tautomeric composition of AA in the liquid phase by ${ }^{1} \mathrm{H}$ NMR: AA (neat; $80 \%$ enol), (chloroform; 86\% enol), (DMSO; 63\% enol) [17]. ${ }^{1} \mathrm{H}$ NMR shows that the enol form of AA prevails in the both gas and liquid phase (in inert solvents) at all temperatures. In these conditions, a strong hydrogen bond is created that can stabilize the enol tautomer [16].

Fokendt et al investigated intermolecular exchanges on the keto-enol form of AA by using ${ }^{1} \mathrm{H}$ NMR spectroscopy in the gas and liquid phase at 445-373 K. According to their results, the enol form is stable and its concentration is higher in the gas phase than in the liquid phase [11]. Thermodynamic parameters of keto-enol forms for AA derived from a Van't Hoff

fitting, integrated by ${ }^{1} \mathrm{H}$ NMR spectra are $\Delta \mathrm{G}_{\text {enol-keto }}^{\mathrm{o}}=-2.2 \mathrm{kcal} . \mathrm{mol}^{-1}, \Delta \mathrm{H}^{\mathrm{o}}$ enol-keto $=-4.6$ 
kcal.mol ${ }^{-1}$ and $\Delta \mathrm{S}_{\text {enol-keto }}^{\mathrm{o}}=-8.26 \mathrm{cal} \cdot \mathrm{mol}^{-1} \cdot \mathrm{K}^{-1}$ in the gas phase and $\Delta \mathrm{G}_{\text {enol-keto }}^{\mathrm{o}}=-0.91 \mathrm{kcal} \cdot \mathrm{mol}^{-}$ ${ }^{1}, \Delta \mathrm{H}^{\mathrm{o}}$ enol-keto=-2.8 kcal.mol ${ }^{-1}$ and $\Delta \mathrm{S}_{\text {enol-keto }}^{\mathrm{o}}=-6.39 \mathrm{cal}^{\mathrm{mol}} \mathrm{mol}^{-1} \cdot \mathrm{K}^{-1}$ in the liquid phase. These results are discussed in terms of structural differences and dielectric solvent effects. According to ${ }^{1} \mathrm{H}-\mathrm{NMR}$ studies, thermodynamic results show that decreasing temperature ranges increase equilibrium constants and lead to a high enol content of acetylacetone which is energetically favored in all phases [11]. The vibration analyses and its deuterated analogues of acetylacetone have been assigned by Tayyari et al [18]. Deconvolutions of the infrared spectra were shown broad and strong band of acetylacetone and it's deuterated at $1600 \mathrm{~cm}^{-1}$ region. This is because of creating a strong hydrogen bond and relatively chelated ring which exist in enol form. In another study on AA molecule, Roy et al. [19], investigated and computed the possible structure for the transition state and the potential energy barriers for the interconversion between keto and enol. Furthermore, it was found that in the solution phase the ratio of the keto-enol forms depends on the solvent polarity. In polar solvents such as water and DMSO, the keto tautomer prevails due to the higher dipole moment of the keto form in polar solvents.

Thermodynamic factors of enol and keto forms for methyl acetoacetate (MAA) $\left(\mathrm{R}_{1}=\mathrm{CH}_{3}\right.$, $\mathrm{R}_{2}=\mathrm{H}$, and $\mathrm{R}_{3}=\mathrm{CH}_{3}$ ) obtained from a van't Hoff equation integrated by ${ }^{1} \mathrm{H}$ NMR results are $\Delta \mathrm{G}^{0}(\mathrm{~g})=\mathrm{G}^{0}(\mathrm{keto})-\mathrm{G}^{0}(\mathrm{enol})=0.08 \mathrm{kcal} \cdot \mathrm{mol}^{-1}, \Delta \mathrm{S}^{0}(\mathrm{~g})=9.93 \mathrm{cal} \cdot \mathrm{mol}^{-1} \cdot \mathrm{K}^{-1}, \Delta \mathrm{H}^{0}(\mathrm{~g})=3.04$ kcal.mol ${ }^{-1}$ in the gaseous phase and $\Delta \mathrm{G}^{0}(1)=-1.89 \mathrm{kcal} . \mathrm{mol}^{-1}, \Delta \mathrm{S}^{0}(1)=6.07 \mathrm{cal} . \mathrm{mol}^{-1} \cdot \mathrm{K}^{-1}$, $\Delta \mathrm{H}^{0}(\mathrm{l})=-0.08 \mathrm{kcal}^{\mathrm{mol}}{ }^{-1}$ in the liquid phase [11]. These outcomes show that decreasing temperature ranges increases equilibrium constants and leads to a great enol content of methyl acetylacetone, which is energetically favored in the gas phase. Some studies of ${ }^{1} \mathrm{H}$ NMR on MAA show that exclusively the keto form exists in the liquid at high temperature $[7,11]$. 
Belova et al. studied the structural properties of MAA by gas electron diffraction (GED), DFT, and IR spectroscopy. These results indicated a mixture of $80 \%$ enol form and $20 \%$ keto form [20]. According to DFT calculations, exists only one stable enol form [3, 20] but GED analysis cannot separate between keto conformers. The IR spectrum approves the presence of both enol and keto forms. The relative energies $(\Delta \mathrm{E}=0.5,1.86,4.73,4.76)$, relative free energies $\left(\Delta \mathrm{G}^{0}=-2.11,-0.75,2,2\right)$ and tautomeric composition obtained with the (MP2/6-31G (d, p), MP2/6.311G (2d, f), B3LYP/6-31G (d, p), B3LYP/6-31++G (d, p)) computational methods, receptively. The data show that the MP2 method predicts a strong favorite for the keto forms, whereas the B3LYP method predicts a favorite for the enol tautomer [20].

Ethyl acetoacetate (EAA) is the ethylester of acetoacetic acid $\left(\mathrm{R}_{1}=\mathrm{CH}_{3}, \mathrm{R}_{2}=\mathrm{H}\right.$, and $\left.\mathrm{R}_{3}=\mathrm{C}_{2} \mathrm{H}_{5}\right)$. A measurable method combined experimental-computational approach (CECA)[21], which provided accurate results cheaper and faster than other methods, has been established and is useful for the detection of tautomer ratios of EAA in solvents (acetonitrile, methanol, and chloroform). By using the MP2/cc-pVDZ and MP2/cc-pVTZ method the enol form percentage $(6 \%)$ in acetonitrile and methanol solvent resulted. The extrapolation technique generates the enol ratio $(10 \%)$ in the chloroform, and then the results are obtained using the MP2/cc-pVDZ (13\%) and MP2/cc-pVTZ (11\%) basis sets in chloroform. The theoretical data indicates similar results to experimental studies, for the solvent's ability in the stabilization of enol tautomer ( $\left.\mathrm{Gas}>\mathrm{CHCl}_{3}>\mathrm{MeOH}>\mathrm{CH}_{3} \mathrm{CN}\right)[21]$. FT-IR is a very useful device that makes active almost all the organic molecules in the IR range. The FT-IR spectrum in the solvents shows two bands for keto form (symmetric and asymmetric $\mathrm{C}=\mathrm{O}$ stretching bands) at about $1700 \mathrm{~cm}^{-1}$ and two bands for enol $(\mathrm{C}=\mathrm{O}$ and $\mathrm{C}=\mathrm{C}$ stretching bands $)$ at about $1600 \mathrm{~cm}^{-1}$ [21]. The experimental results approve that the solvent effects have an important difference in keto-enol equilibrium in EAA. Equilibrium constants and the enol content from the experimental ${ }^{1} \mathrm{H}$ NMR technique are calculated as $0.39-28 \%$ in carbon tetrachloride, 0.081 - 
$7.5 \%$ in chloroform, $0.062-5.8 \%$ in methanol, $0.078-7.2 \%$ in ethanol, and $0.052-4.9 \%$ in acetonitrile at $33{ }^{\circ} \mathrm{C}[16] .{ }^{1} \mathrm{H}$ NMR spectra of EAA between 377 and $417 \mathrm{~K}$ show a mixture of both keto and enol tautomers. Thermodynamic parameters of enol and keto forms for EAA are $\Delta \mathrm{G}^{0}(\mathrm{~g})=\mathrm{G}^{0}($ keto $)-\mathrm{G}^{0}(\mathrm{enol})=0.08$ kcal. $\mathrm{mol}^{-1}, \Delta \mathrm{S}^{0}(\mathrm{~g})=10.38$ cal.mol ${ }^{-1} \cdot \mathrm{K}^{-1}, \Delta \mathrm{H}^{0}(\mathrm{~g})=3.17$ kcal.mol ${ }^{-1}$ in gas phase and $\Delta \mathrm{G}^{0}(\mathrm{l})=-1.55 \mathrm{kcal} . \mathrm{mol}^{-1}, \Delta \mathrm{S}^{0}(\mathrm{l})=5.81 \mathrm{cal} \cdot \mathrm{mol}^{-1} \cdot \mathrm{K}^{-1}, \Delta \mathrm{H}^{0}(\mathrm{l})=0.18$ kcal.mol ${ }^{-1}$ in liquid phase. According to the upper obtained values, $\mathrm{K}_{\mathrm{eq}}$ and enol percentage could be calculated. According to ${ }^{1} \mathrm{H}$ NMR studies, thermodynamic results show that decreasing temperature ranges increases the equilibrium constants and causes a high enol percentage of EAA which is energetically preferred in all phases [11]. The data showed that in the gas phase of ethyl acetoacetate is the enol form more stable while it has little stability in the neat phase. However, the keto form is favored entropically in both phases [11].

Ethyl 2-methyl acetoacetate (EMA) is a $\beta$-ketoester with $\mathrm{R}_{1}=\mathrm{R}_{2}=\mathrm{CH}_{3}$ and $\mathrm{R}_{3}=\mathrm{C}_{2} \mathrm{H}_{5}$. The exchange of $\alpha$-substituents results in a steric effect between the R1 and R3 group protons. The enol ratio reduces because of the effect of alkyl substitution in the $\alpha$-position for $\beta$ dicarbonyls which have a mixture of inductive effects and steric effects. Substitution of alkyl groups at the $\alpha$-position should increase the electron density. Burdett and Rogers [22] by using ${ }^{1} \mathrm{H} \mathrm{NMR}$, calculated at $33{ }^{\circ} \mathrm{C}$ the equilibrium constants $(0.05,4.3,0.09,0.28)$ in EMA, AA, EAA, EBA, respectively. Ethyl 2-methyl acetoacetate (EMA) is an allelochemical molecule that has an inhibitory effect on the growth of green algal species and bloomforming cyanobacterium [23- 24]. ${ }^{1} \mathrm{H}$ NMR and Gas chromatography-mass spectrometry (GC-MS) was used in the identification of the allelopathic compounds. The mass spectrum in these allelopathic compounds had shown the weight of EMA $(80 \%)$. It was revealed that EMA has a strong inhibitory activity on cyanobacteria [25-26].

Benzyl acetoacetate (BAA) $\left(\mathrm{R}_{1}=\mathrm{CH}_{3}, \mathrm{R}_{2}=\mathrm{H}\right.$, and $\left.\mathrm{R}_{3}=\mathrm{CH}_{2} \mathrm{Ph}\right)$ is a $\beta$-ketoester, with different substitution effects (electron-withdrawing, steric and mesomeric effects) which are effective 
on H-bond strength. Tayyari et al. [4], compared the hydrogen bond strength of AA and dimethyl oxaloacetate (DMOA) with BAA and concluded that $\mathrm{E}_{\mathrm{HB}}$ estimated of $\mathrm{AA}$ is higher than that in BAA, and DMOA in the gas phase which is demonstrated as AA> BAA> DMOA. By examination of all possible conformers and tautomers, were existed 22 stable cisenol, 28 stable trans-enol, and five keto conformers at the DFT levels. The ${ }^{1} \mathrm{H}$ NMR calculations, all taken at room temperature, show that solvent effects are different on the keto-enol equilibrium of BAA and the percentage of enol form is as: $9 \%$ in chloroform, $3 \%$ in methanol, $3 \%$ in acetonitrile, and $<2 \%$ in acetone and DMSO.

According to IR spectra of the most stable enol and keto forms of BAA, the weak IR band in the $\mathrm{CCl}_{4}$ phase at $289 \mathrm{~cm}^{-1}$ and $316 \mathrm{~cm}^{-1}$ are assigned to the $\mathrm{O} \ldots \mathrm{O}$ stretching which in AA appears at about $360 \mathrm{~cm}^{-1}$ [18] and so, the strength of the hydrogen bond in the enol form of the AA compound is fewer than the enol form of the BAA compound. According to the theoretical and experimental values, the hydrogen bond energy of the most stable enol conformer of BAA is $56.7 \mathrm{~kJ} \mathrm{~mol}^{-1}$ which is about $10 \mathrm{~kJ} \cdot \mathrm{mol}^{-1}$ less than that of AA. Both NMR and IR spectroscopy methods indicate a mixture of keto and enol tautomers of BAA with more than $80 \%$ of keto content in all considered solutions [4].

Ethyl benzoylacetone (EBA) $\left(\mathrm{R}_{1}=\mathrm{Ph}, \mathrm{R}_{2}=\mathrm{H}, \mathrm{R}_{3}=\mathrm{C}_{2} \mathrm{H}_{5}\right)$ is a $\beta$-ketoester, with different substitution effective on H-bond strength. Tayyari et al. [5], studied structure molecule and vibrational assignments of present tautomers of EBA by theoretical and experimental methods. Using spectroscopy indicates the existence of a mixture of keto-enol forms in EBA. The ${ }^{1} \mathrm{H}$ NMR results also show that the solvents have different effects on keto-enol equilibrium in EBA and the percentage of the enol form is $46 \%$ in benzene, $17 \%$ in chloroform, $27 \%$ in methanol, $8 \%$ in acetonitrile, $9 \%$ in DMSO. According to the study on BAA, it can be concluded that the percentage of enol in BAA is less than EBA [4- 5]. The OH/OD stretching and OH/OD out-of-plane bending modes were obtained by NMR and IR 
spectrum. The obtained results from the theoretical and experimental methods show that the hydrogen bond is weaker in the enol form of EBA than in the enol form of AA. According to the theoretical and experimental calculations, 54\% keto form was reported for the EBA molecule, in all considered solutions [5].

\section{Experimental}

MAA, EAA, EMA, ethanol $\left(\mathrm{C}_{2} \mathrm{H}_{5} \mathrm{OH}\right)$, carbon tetrachloride $\left(\mathrm{CCl}_{4}\right)$, and acetonitrile $\left(\mathrm{CH}_{3} \mathrm{CN}\right)$ were purchased from Sigma with a purity of $>99 \%$. The Bomem B-154 Fourier Transform was used to study the FT-IR spectrum. Also, the Far-IR spectrum was collected from Thermo Nicolet NEXUS 880 FT-IR spectrometers equipped with a DTGS/polyethylene detector and a solid substrate beam splitter in $\mathrm{CCl}_{4}$ solution using the Perkins Elmer lambda 25 spectrophotometer. The ultraviolet absorption spectrum was investigated. All $\beta$-ketoester compounds were dissolved in ethanol, carbon tetrachloride, and acetonitrile solvents. Avance Bruker-400 MHz spectrometer was used to record the ${ }^{1} \mathrm{H}$ NMR spectrum.

\section{Method of analysis}

In this study, computational software including Gaussian 09 [27], Gauss View 5 [28], NBO 5.0 [29], and AIM2000 [30] programs were used for all the quantum calculations and investigation of the geometrical parameters of $\beta$-ketoesters. All of the conformer's energies were calculated and compared with the most stable keto and enol conformer. The thermodynamic parameters of balanced keto-enol forms were calculated in the gas phase and solution phases including acetonitrile, carbon tetrachloride, and optimized by using B3LYP/6-311++G** levels [31]. Additionally, these parameters were calculated in solutions $\left(\mathrm{C}_{2} \mathrm{H}_{5} \mathrm{OH}, \mathrm{CCl}_{4}\right.$, and $\left.\mathrm{CH}_{3} \mathrm{CN}\right)$ by using the SCRF-PCM method [32- 33]. The electron charge density $(\rho)$ and its Laplacian $\left(\nabla^{2} \rho\right)$ were calculated by the AIM program to estimate the nature and strength of the IHB. In addition to bond order and Charge analysis calculations, the 
second-order interaction energies $\mathrm{E}^{(2)}$ [34] were performed at the B3LYP/6-311++G** level using the NBO 5.0 program.

\section{Results and discussion}

\subsection{Tautomeric composition}

Tautomeric equilibrium is one of the most important conversions in nature which has been studied by many researchers who investigated keto-enol tautomer in $\beta$-ketoesters [3, 7]. In this study, all stable enol forms are called "AU" and all stable keto forms are called "K" in $\beta$ ketoester compounds. Cis (I) and Trans (II) are isomeric enol tautomers. Also, in unsymmetrical $\beta$-ketoesters compounds, Cis enol is more stable than Trans isomer due to the formation of the intramolecular hydrogen bonds. Figure 1 shows the keto-enol equilibrium in different $\beta$-ketoesters. Due to the electronic properties and nature of the solvents, the ketoenol equilibrium position for the $\beta$ - ketoesters is changed. As shown in Figure 2, to form an enolated species of $\beta$-ketoesters type I, the most acidic proton is first eliminated from the $\mathrm{C} 3$ atom to give enolated type II. The negative charge could transfer to O1 (structure III) or O2 (structure IV). However, structure III is more favorable than structure IV because of the more positive charge at $\mathrm{C} 2$. As a result, AU-Enol is more stable than BU-Enol of $\beta$-ketoesters as shown in Figure 1 [3]. Figures S1 and S2 (supplementary materials) are show the most stable enol and keto tautomers of AA, MAA, EAA, EMA, EBA, and BAA, respectively. The hydrogen bond strength of the $\beta$-ketoesters was compared with the AA, BAA, and EBA [4- 5, 18]. In Figure S1, the energy difference between the most stable cis-enol form and keto form of the mentioned compounds (in parentheses) and the hydrogen bond energy calculated from the energy difference between cis and trans isomers of enol form (in brackets) computed with B3LYP/6-311++G** level are shown. The hydrogen bond energy of the most stable enol 
forms of $\beta$-diketone compounds is as AA (66.4), MAA (56.8), EAA (57.7-57.6), EMA (63.763.5), EBA (56.4-56.3), and BAA (56.7-57.1).

In Table 1, all thermodynamic parameters of stable enol and keto forms of $\beta$-ketoester compounds (MAA and EAA, EMA, BAA, EBA) including zero-point energy, entropy, enthalpy, and relative energy $\left(\Delta \mathrm{E}^{\circ}, \Delta \mathrm{E}_{0}^{\circ}, \Delta \mathrm{H}^{\circ}, \Delta \mathrm{S}^{\circ}, \Delta \mathrm{G}^{\circ}\right)$ are shown and compared with AA. Equilibrium constants and enol content of $\beta$-ketoester compounds according to van't Hoff equation and using the thermodynamic equations $\left(\Delta \mathrm{G}=-\mathrm{RT} \ln \left(\mathrm{K}_{\mathrm{eq}}\right), \Delta \mathrm{G}^{0}=\left(\mathrm{G}^{0} \mathrm{Keto}^{-} \mathrm{G}^{0}\right.\right.$ Enol $\left.)\right)$ were calculated in the gas phase and also in carbon tetrachloride and acetonitrile solvents. The results show that the ratio of enol form in the polar solvent decreases and the probability of the presence of the keto form increases. In Table 1, the relative energy of stable cis-enol forms and stable keto forms in the gas and solution phases are given. The relative energy of the most stable enol and keto forms is as follows: MAA (17.05-19.30), EAA (1.70-21.34), EMA (1.75-12.44), EBA (1.8-17.8), BAA (0.2-17.3) in $\mathrm{kJ}^{\mathrm{m}} \mathrm{mol}^{-1}$. Also, the enol and keto tautomer are favored enthalpically and entropically, respectively.

Tayyari et al. shown for a type of b-ketosterer include dimethyl oxaloacetate (DMOA) with twelve keto conformers and using relative energy result suggested that keto forms do not appear as major content in the gas phase[3].

\subsection{Molecular geometry and intramolecular H-bond strength}

The AIM topological parameters including $\mathrm{E}_{\mathrm{HB}}$ (hydrogen bond strength, $\mathrm{kJ} \cdot \mathrm{mol}^{-1}$ ), $\rho_{\mathrm{BCP}}$ (Bond Critical Point-charge density), $\nabla^{2} \rho_{\text {ВСР }}$ (Bond Critical Point -Laplacian charge density) were obtained using AIM2000 software at the level of B3LYP/6-311++G (d, p). In addition, the relative Gilli's symmetry coordinates $\left(\mathrm{Q}, \mathrm{q}_{1}, \mathrm{q}_{2}\right.$, and $\left.\lambda\right)$ were evaluated [35]. The obtained data are given in Table 2. Also, Table 2 is shown the geometrics effects of the studied $\beta$ ketoesters and compared them with AA, BAA, and EBA [4- 5, 18]. In Table 2, the changes of 
bond length of $\mathrm{O} \ldots \mathrm{O}$ and $\mathrm{O} \ldots \mathrm{H}$ in the $\beta$-ketoester compounds due to the substituting the $\alpha$ and $\beta$ positions are given and compared with AA. The higher the strength of the hydrogen bond of a compound, the shorter the $\mathrm{O} \ldots \mathrm{O}$ and the $\mathrm{O} \ldots \mathrm{H}$ intervals, but the longer the $\mathrm{O}-\mathrm{H}$ bond length and the $\mathrm{OHO}$ angle. However, the bond length of $\mathrm{C}=\mathrm{O}$ and $\mathrm{C}=\mathrm{C}$ in $\mathrm{AA}$ is higher than the $\beta$-ketoesters. Also, the bond length of $\mathrm{C}-\mathrm{C}$ and $\mathrm{C}-\mathrm{O}$ in $\mathrm{AA}$ is shorter than the $\beta$ ketoesters [3]. These observations indicate that the $\beta$-electron delocalization of the chelate ring in $\beta$-ketoesters is not like AA.

Higher values of $\mathrm{q}_{1}, \mathrm{q}_{2}, \mathrm{Q}$, and lower values of $\lambda$ in $\beta$-ketoesters compared to AA values demonstrate that these compounds have a weaker bond than AA. The results of Table 2 indicate that the strength of IHB of the studied molecules is as follows: AA> EMA> EBA> $\mathrm{EAA} \sim \mathrm{MAA} \sim \mathrm{BAA}$.

Table 3 presents the results of $\delta_{\mathrm{OH}}$ (proton chemical shift) of ${ }^{1} \mathrm{H} \mathrm{NMR}$, the $v_{\mathrm{OH}}, \gamma_{\mathrm{OH}}$ (stretching and out-of-plane bending frequencies), $v_{\mathrm{C}=\mathrm{O}}, v_{\mathrm{C}=\mathrm{C}}, v_{\mathrm{O}} \ldots \mathrm{O}$ (stretching) in enol form and $v_{\mathrm{C}=\mathrm{O}}, v_{\mathrm{CH} 2}$ in keto form of FT-IR studies (in the $\mathrm{CCl}_{4}$ solution). The obtained results are confirmed by experimental and theoretical results (Table S1-6) (supplementary materials) while the BAA and EBA assignments were reported by Tayyari et al.[4, 5, 36].

All experimental chemical shifts, reported as $\mathrm{ppm}$, in $\mathrm{CDCl}_{3}$ at room temperature were obtained from the literature. In the $\mathrm{H}-\mathrm{NMR}$ results, the $\mathrm{OH}$ group of the enol form corresponding to AA appears at $\delta_{\mathrm{OH}}=15.4 \mathrm{ppm}$ but for EAA, MAA, EMA, and EBA, it emerges at about $\delta_{\mathrm{OH}}=12 \mathrm{ppm}$. In IR spectroscopy, the stretching frequencies $(\mathrm{vOH})$ of the $\beta$ ketoesters shift to higher values (blueshift) and the out-of-plane bending frequencies $(\gamma \mathrm{OH})$ shift to lower values (redshift) in comparison with AA. From the above results, it can be concluded that the trend of hydrogen bond strength for $\beta$-dicarbonyl molecules is as follows: $\mathrm{AA}>\mathrm{EMA}>\mathrm{EBA}>\mathrm{BAA} \sim \mathrm{EAA} \sim \mathrm{MAA}$. 
The stretching vibrations at $1600 \mathrm{~cm}^{-1}$ are assigned to the $\mathrm{C}=\mathrm{C}, \mathrm{C}=\mathrm{O}$ stretching of the $\beta$ ketoester enol form, which are also coupled to $\mathrm{OH}$ and $\mathrm{CH}$ in-plane bending vibrations[18, 21].

The symmetric and asymmetric stretching peaks of $\mathrm{CH}_{2}$ of keto forms in the $\beta$-ketoesters are observed at high frequencies, as well as two strong peaks in the region of about $1700 \mathrm{~cm}^{-1}$ are related to stretching vibrations $(\mathrm{C}=\mathrm{O})$ of keto forms of $\beta$-ketoesters [21, 37].Also keto forms in the $\mathrm{CH}_{2}$ stretching region are not distinguishable in $\mathrm{AA}[36]$. Usually, in the $\beta$-ketoesters most of the frequencies generated in the keto form tend to be blueshift.

Two bands at $1727-1707 \mathrm{~cm}^{-1}$ shown the presence of keto forms in AA via stretching $(\mathrm{C}=\mathrm{O})$ vibrations, These bands in Raman spectrum of AA was observed at about 1719-1697 $\mathrm{cm}^{-1}$, while the mentioned bands in IR spectra of $\beta$-ketoesters with a blueshift is appeared at 1740$1720 \mathrm{~cm}^{-1}$. Schiering et al reported the band of $1759 \mathrm{~cm}^{-1}$ in the $\mathrm{CCl}_{4}$ IR spectra DMOA for $\mathrm{C}=\mathrm{O}$ stretching vibration methoxy group in enol form [37].

\subsection{NBO analysis}

Using the NBO 5.0 method at the level of B3LYP/6-311++G(d, p), The Wiberg bond orders, the Charge analysis, and the second-order energy between the occupied orbitals of one molecule and the unoccupied orbitals were investigated [29, 34].

\subsubsection{Wiberg bond orders}

For comparison, the Wiberg bond orders [38] for both the most stable enol and keto forms of the $\beta$-ketoesters are shown in Table 4 . This table shows that the bond order of $\mathrm{C} 3=\mathrm{C} 2$ in the enol form of $\beta$-ketoesters is significantly greater than that of AA. In addition, this Table shows that the bond strength of $\mathrm{C} 3-\mathrm{C} 4, \mathrm{O} 1-\mathrm{C} 2, \mathrm{O} 1 \ldots \mathrm{O} 2$, and $\mathrm{O} 2=\mathrm{C} 4$ in the target molecules is shorter in comparison to AA in enol form. The $\mathrm{O} \ldots \mathrm{H}$ bond order of AA is higher than the 
$\beta$-ketoesters, so the Wiberg bond order analysis confirms that the intramolecular hydrogen bond is weaker in $\beta$-ketoesters $[6,8]$. On the other hand, the replacement of the R3 group with the ester groups prevents the separation of electrons in the $\mathrm{C} 2=\mathrm{C} 3-\mathrm{C} 4=\mathrm{O} 2$ of the chelate ring. As a result, in keto forms, the order of $\mathrm{C}=\mathrm{O}$ bond in $\mathrm{AA}$ is higher relative to $\beta$ ketoesters compounds.

\subsubsection{Charge analysis}

Table 5 shows the charge distribution calculated by the NBO method for the optimal geometries of $\beta$-ketoesters. The analysis of the data in Table 5 shows that the substitutions affect the charge distribution of carbon and oxygen atoms in $(\mathrm{O} 1-\mathrm{C} 2=\mathrm{C} 3-\mathrm{C} 4=\mathrm{O} 2)$. The presence of an electron-donating group at the R3 position increases the positive charge around $\mathrm{C} 4$ and decreases the positive charge around $\mathrm{C} 2$. The outcomes presentation that by increasing the hydrogen acidity of the bridge from AA to $\beta$-ketoesters, the hydrogen bond strength of the ester compounds is reduced[8].

\subsubsection{Electron delocalization}

In Table 6, the second-order calculated energy $\mathrm{E}^{(2)}$ between the donor-acceptor orbitals in the different $\beta$-ketoesters conformers and AA is listed. According to Table 6 , the interaction between $\pi^{*}{ }_{\mathrm{C} 4=\mathrm{O} 2}$ as the donor and $\pi^{*}{ }_{\mathrm{C} 3=\mathrm{C} 2}$ as the acceptor has the highest energy in $\beta$ ketoesters. The results show that the second-order energies are reduced relative to AA due to the reduction of the electron location of the electrons in the chelate ring of esters, which corresponds to a decrease in the hydrogen bond strength of these compounds relative to AA. Also, the energy of the interaction between $\pi^{*} \mathrm{C} 4=\mathrm{O} 2$ and $\pi^{*}{ }_{\mathrm{C} 3=\mathrm{C} 2}$ is almost the same in MAA, $\mathrm{EAA}$, and $\mathrm{BAA}[8]$. In $\mathrm{EBA}$, this interaction increases due to the presence of phenyl substitution and the steric effect but in the molecule EMA, it reduces due to the presence of 
methyl substitution at $\alpha$-position and the steric effect [39]. On the other hand, the electrons interacting energies of $\mathrm{LP}(2) \mathrm{O} 1 \rightarrow \pi^{*} \mathrm{C} 2-\mathrm{C} 3$, and $\mathrm{LP}(2) \mathrm{O} 2 \rightarrow \sigma^{*} \mathrm{O} 1-\mathrm{H} 1$ in the esters are lower than AA, which is in accord with the decrease in the hydrogen bonding of the esters. The value of interaction energy for enol and keto tautomers in Table 6 shows LP2(O3) $\rightarrow \pi^{*}(\mathrm{C} 4-$ $\mathrm{O} 2), \mathrm{LP} 1(\mathrm{O} 3) \rightarrow \sigma^{*}(\mathrm{C} 4-\mathrm{O} 2)$ to are almost equal, which confirms the existence of both keto and enol tautomers in the studied compounds [8]. However, by containing lone pair at the methoxy $\mathrm{LP} 2(\mathrm{O} 3) \rightarrow \pi^{*}(\mathrm{C} 4-\mathrm{O} 2)$ connected to $\mathrm{C} 4$, a strong interaction is created. Such an interaction can occur only in a $\mathrm{C}=\mathrm{O}$ double bonds. So, these interaction indicates which the keto form more stabilized by hyper conjugation in the $\beta$-ketoesters.

the values of the interaction energy of $\mathrm{CR}(1) \mathrm{O} 1 \rightarrow \mathrm{RY}(1) * \mathrm{C} 2, \mathrm{LP}(1) \mathrm{O} 2 \rightarrow \mathrm{RY}(1)^{*} \mathrm{C} 4$, $\mathrm{LP}(2) \mathrm{O} 2 \rightarrow \sigma^{*}(\mathrm{O} 3-\mathrm{C} 4)$, and $\mathrm{LP}(2) \mathrm{O} 2 \rightarrow \sigma^{*}(\mathrm{C} 4-\mathrm{C} 3)$ indicate that these amounts in keto form are higher than that of the enol form, which can be deduced that the keto form is higher volume than the enol form.

\subsection{Electronic properties}

\subsubsection{UV-Visible spectra analyses}

The UV absorption results including the calculated absorption wavelengths $(\lambda)$, oscillator strengths (f), and experimental data, equilibrium constant $\left(\mathrm{K}_{\mathrm{eq}}\right)$, and ratio enol form of the title compounds calculated by TD-DFT/B3LYP/6-311++G(d, p) are given Table 7. These data can be related to their consistent molecular structure and electron transitions[40].

The theoretical and experimental electronic absorption spectra of the target molecules in acetonitrile, ethanol, and carbon tetrachloride solvents are reported in Table 7 using polarizable continuum model PCM in solvent for enol and keto forms in $\beta$-ketoesters and AA. Besides, the related UV-Vis spectra are shown in Fig S3-5 (supplementary material) for 
MAA, EAA, EMA, BAA, and EBA molecules in solvent different (polar or nonpolar) which for example the EAA, EBA, and BAA molecules are displayed in Fig 3-5.

The absorption maximum for AA has a wide peak in about $265 \mathrm{~nm}$ region, which is related to the chelating ring by the $\pi \rightarrow \pi^{*}$ band transitions[40- 41]. While the absorption maximum and enol percentage of increases in non-polar solution[42]. In the gas and solvent phases, with increasing hydrogen bond strength, the absorption wavelengths have redshifts. Table 7 shows that the absorption spectra in polar solvent are about $200-260 \mathrm{~nm}$ and in non-polar solvent in the range $260-300 \mathrm{~nm}[43]$.

The results show that the $\lambda$ max values in AU2 and $\mathrm{K} 2 \beta$-ketoesters are very similar to AU1 and K1. So, wavelengths of AU2 and K2 are not reported in Table 7.

The theoretical and experimental results of UV analysis for EMA, MAA, and EAA the most stable keto-enol tautomerism show that in MAA, EAA, molecules, two peaks have been observed in the regions below $200 \mathrm{~nm}$ and above $220 \mathrm{~nm}$, which are related to the keto form and the chelate ring in the enol form, respectively [44]. While in EMA due to the presence of methyl group at $\alpha$-position in the wavelengths were shifted to higher numbers (redshift).

The data in Table 7 for the BAA and EBA molecules show that both of them contain phenyl rings, that in the BAA molecule, the phenyl is attached to the ester group, while in the EBA molecule, the phenyl group is attached to the carbonyl. In the EBA, three bands of about 290, 240, and $200 \mathrm{~nm}$ have been observed experimentally and theoretically, which are assigned to the transfer of the phenyl group, the enol chelate rings, and the keto form, respectively. In BAA, only broad peak of about 230-300 $\mathrm{nm}$ [45] to the phenyl group and a bands at about 210 nm have been observed, which are related to the solvent cutoff. Also, no transfer band for enol form was observed in polar solvent because ratio the enol form is very low in NMR data [4]. However in the polar solvent, a strong pick has been demonstrated below $200 \mathrm{~nm}$ region which is related to the keto form. 
The keto-enol equilibrium is very sensitive to the nature of the solvent. This means that in the carbon tetrachloride solvent it was focused to the enol adsorption band but in the acetonitrile solvent the keto adsorption band was distinguished. About the use of polar protic ethanol as solvent, it was observed that the keto intensity band is higher than the enol band[42, 45].

The peaks observed in the about $200 \mathrm{~nm}$ region in Fig 3-4 are related to polar solvents that have a high absorption coefficient that indicates the keto shape in these solvents. Fig 5, only one band at $260 \mathrm{~nm}$ is shown of the enol form in a non-polar solvent. Some researchers have been determined equilibrium constants and the ratio enol form for $\beta$-diketones by the technique in UV/Vis spectrum [43, 45- 46]. The equilibrium constant is obtained from the absorption band ratios from the experimental values and the ratios of oscillator strengths in keto-enol forms via the TD-DFT theoretical approach.

The equilibrium constants obtained from UV in Table 7 and their Comparison with equilibrium constants via thermodynamics techniques in Table 1, it resulted that as the equilibrium constant values increases, the keto content rises. Therefore, in the gas and solution phase, the keto forms have more polarity than the enol forms, which is in good agreement with the reported results obtained from UV on the similar molecules [45].

\subsubsection{Frontier molecular orbitals (FMO)}

It is obvious that TD-DFT method are more likely to provide more HOMO $\rightarrow$ LUMO and HOMO-n $\rightarrow$ LUMO $+\mathrm{n}$ transition corresponds to the enol and keto forms, respectively. Also, the orbital transmission of $\mathrm{HOMO} \rightarrow$ LUMO takes place at a wavelength of about $230 \mathrm{~nm}$ according to the theoretical calculations and at a wavelength of about $240 \mathrm{~nm}$ according to the experimental results in enol form of $\beta$-ketoesters (Table 7). So these changes occurred towards higher wavelengths (red shift). In the keto form, a wavelength of about $200 \mathrm{~nm}$ was observed by the orbital transfer theory (HOMO-n $\rightarrow$ LUMO $+n$ ). 
Frontier molecular orbital images for the two stable forms of keto and enol of the $\beta$ ketoesters and AA molecules are shown in Fig 6-7. According to this figure, the energy gap values in the keto and enol forms are about 6 and $5 \mathrm{eV}$, respectively. The low energy gap in the enol $\beta$-ketoesters molecule means that enols are lower chemical reactivity and higher kinetic stability than keto form [47]. Also, the low energy gap in the enol means that it is softer than the keto form. A comparison of the experimental wavelengths and their HOMOLUMO gaps in enol form shows that the wavelength is about $240 \mathrm{~nm}$ and is related to the envelope distance of about $5 \mathrm{eV}$. Also, the wavelength $<200 \mathrm{~nm}$ is related to the gap value of about $6 \mathrm{eV}$ of the keto shape, which confirms the presence of both enol and keto forms in the sample [48]. According to Table 1 and Table 7, the dipole moments are increased and the electronic gap $(\Delta \mathrm{E})$ between HOMO and LUMO are more in the keto form than in the enol form.

\section{Conclusion}

Intramolecular hydrogen bonds for MAA, EAA, EMA, EBA, and BAA, compounds were compared with AA molecule theoretically by using the DFT method and topological parameters (AIM), NBO, geometric parameters, and experimentally by using NMR, IR, and UV-Vis spectroscopy. All these methods showed that the strength of the hydrogen bond in the different molecules is as follows: $\mathrm{AA}>\mathrm{EMA}>\mathrm{EBA}>\mathrm{BAA} \sim \mathrm{EAA} \sim \mathrm{MAA}$. The results also show that electron donor groups such as the alkoxy group in the $\beta$-position of $\beta$-ketoesters decrease the strength of the hydrogen bond in comparison with the AA. On the other hand, the presence of methyl substitution at $\alpha$-position and its steric effect in the EMA creates a lower resonance and decreases the hydrogen bond strength in comparison with AA. According to NMR, UV-Vis, and FT-IR spectroscopy, both tautomers exist in $\beta$-ketoesters molecules. The NMR results indicated that the AA molecule has a higher $\mathrm{OH}$ chemical shift 
$(\delta \mathrm{OH})$ than the $\beta$-ketoesters. FT-IR spectroscopy showed that the $\mathrm{OH}$ stretching frequency in

$\beta$-ketoesters is higher, while the $\mathrm{O} \ldots \mathrm{H}$ and $\mathrm{O} \ldots \mathrm{O}$ bends stretching are observed at a lower frequency compared to AA. Besides, in the IR spectra, two strong peaks are seen at about $1700 \mathrm{~cm}^{-1}$ that is related to keto forms.

In the UV-Vis spectrum, two peaks have been observed in $\beta$-ketoesters that show the presence of enol and keto forms, simultaneously. Also, equilibrium constants of solvents computed computationally and experimentally, show that the amount of enol form is reduced in both polar and nonpolar solvents. In addition, the results show that there is a higher probability of the presence of keto form in the solvents.

\section{Acknowledgment}

The authors of this work appreciate the financial support of the Ferdowsi University of Mashhad, Iran (grant No. 45820).

\section{Declaration of interests}

The authors declare that they have no known competing financial interests or personal relationships that could have appeared to influence the work reported in this paper.

\section{Reference}

[1] Tayyari S.F, Zahedi-Tabrizi M, Azizi-Toupkanloo H, Hepperle S.S, Wang Y.A, (2010) The nature of intramolecular hydrogen bond in 2-nitromalonaldehyde, Chemical Physics 368:62-65

[2] Belova N.V, Oberhammer H, Trang N.H., Girichev G.V (2014) Tautomeric properties and gas-phase structure of acetylacetone, The Journal of organic chemistry 79:5412-5419

[3] Tayyari S.F, Salemi S, Tabrizi M.Z, Behforouz M (2004) Molecular structure and vibrational assignment of dimethyl oxaloacetate, Journal of molecular structure 694:91-104

[4] Tayyari S.F, Naghavi F, Pojhan S, McClurg R.W, Sammelson R.E (2011) Conformational analysis, tautomerization, IR, Raman, and NMR studies of benzyl acetoacetate, Journal of Molecular Structure 987:241254

[5] Tayyari S.F, Chahkandi, S. Mehrani B, McClurg R.W, Keyes C.A, Sammelson R.E (2012) Conformational analysis, tautomerization, IR, Raman, and NMR studies of ethyl benzoylacetate, Journal of Molecular Structure 1015:74-85

[6] Sandler I, Harper J.B., Ho J (2021) Explanation of Substituent Effects on the Enolization of $\beta$-Diketones and $\beta$-Ketoesters, Journal of Chemical Education 98(3):1043-1048 
[7] Schiavoni M, Di Loreto H, Hermann A, Mack H.G, Ulic S, Della Vedova C, (2001) Keto-enol tautomerism in $\beta$-ketoesters: $\mathrm{CH} 3 \mathrm{C}(\mathrm{O}) \mathrm{CHXC}(\mathrm{O}) \mathrm{OY}(\mathrm{X}=\mathrm{H}, \mathrm{Cl}$; Y= CH3, C2H5). Vibrational analyses, NMR spectra and quantum chemical calculations, Journal of Raman Spectroscopy 32:319-329

[8] Belova N.V, Sliznev V.V, Oberhammer H, Girichev G.V (2010) Tautomeric and conformational properties of $\beta$-diketones, Journal of Molecular Structure 978:282-293

[9] Manbeck K.A, Boaz N.C, Bair N.C, Sanders A.M, Marsh A.L (2011) Substituent effects on keto-enol equilibria using NMR spectroscopy, Journal of chemical education 88:1444-1445

[10] Bunkoed O, Davis F, Kanatharana P, Thavarungkul P, Higson S.P (2010) Sol-gel based sensor for selective formaldehyde determination, Analytica chimica acta 659:251-257

[11] Folkendt M.M, Weiss-Lopez B.E, Chauvel Jr J.P, True N.S (1985) Gas-phase proton NMR studies of keto-enol tautomerism of acetylacetone, methyl acetoacetate, and ethyl acetoacetate, The Journal of Physical Chemistry 89:3347-3352

[12] Reguero M, Bernardi F, Bottoni A, Olivucci M, Robb M.A (1991) Chemiluminescent decomposition of 1, 2-dioxetanes: an MC-SCF/MP2 study with VB analysis, Journal of the American Chemical Society 113:1566-1572

[13] Rarh V (2008) Organic synthesis via enolates,

[14] Bassetti M, Cerichelli G, Floris B (1988) Substituent effects in keto-enol tautomerism. Part 3.1 influence of substitution on the equilibrium composition of of $\beta$-dicarbonyl compounds, Tetrahedron 44:2997-3004

[15] Drexler E.J, Field K.M (1976) An NMR study of keto-enol tautomerism in $\beta$ [beta]-dicarbonyl compounds, Journal of Chemical Education 53:392.

[16] Rogers M. T, Burdett J. L (1965) Keto-Enol Tautomerism in $\beta$-Dicarbonyls Studied by Nuclear Magnetic Resonance Spectroscopy: II. Solvent Effects on Proton Chemical Shifts and on Equilibrium Constants, Canadian Journal of Chemistry 43:1516-1526

[17] Cook A.G, Feltman P.M (2007) Determination of Solvent Effects on Keto_Enol Equilibria of 1, 3-Dicarbonyl Compounds Using NMR, Journal of chemical education 84:1827

[18] Tayyari S.F, Milani-Nejad F (2000) Vibrational assignment of acetylacetone, Spectrochimica Acta Part A: Molecular and Biomolecular Spectroscopy 56:2679-2691

[19] Roy P, Biswas S, Pramanik A, Sarkar P (2017) Computational Studies on the Keto-Enol Tautomerism of Acetylacetone.

[20] Belova N.V, Oberhammer H, Girichev G.V (2004) Tautomeric and conformational properties of methyl acetoacetate, $\mathrm{CH} 3 \mathrm{OC}(\mathrm{O})-\mathrm{CH} 2-\mathrm{C}(\mathrm{O}) \mathrm{CH} 3$ : Electron diffraction and quantum chemical study, The Journal of Physical Chemistry A 108:3593-3597

[21] Karabulut S, Leszczynski J (2014) Combining ab initio calculations and Fourier-transform infrared (FT-IR) spectroscopy for quantitative analysis of multicomponent systems in solution:

Tautomer proportions of ethyl acetoacetate, Vibrational Spectroscopy 74:1-5.

[22] Burdett J.L, Rogers M.T (1964) Keto-enol tautomerism in $\beta$-dicarbonyls studied by nuclear magnetic resonance spectroscopy. 1 I. Proton chemical shifts and equilibrium constants of pure compounds, Journal of the American Chemical Society 86:2105-2109

[23] Hong Y, Hu H.-Y, Li F.-M (2008) Growth and physiological responses of freshwater green alga Selenastrum capricornutum to allelochemical ethyl 2-methyl acetoacetate (EMA) under different initial algal densities, Pesticide Biochemistry and Physiology 90:203-212

[24] Yang C.Y, Liu S.J, Ma X.X, Zhou J, Xia C.H (2012) Effects of ethyl 2-methyl acetoacetate (EMA) on the growth of Phaeodactylum tricornutum and Skeletonema costatum, Chemistry and Ecology 28:524-534

[25] Li F.-M, Hu H.-Y (2005) Isolation and characterization of a novel antialgal allelochemical from Phragmites communis, Appl. Environ. Microbiol. 71:6545-6553

[26] Hong Y, Hu H.-Y, Li F.-M (2008) Physiological and biochemical effects of allelochemical ethyl 2-methyl acetoacetate (EMA) on cyanobacterium Microcystis aeruginosa, Ecotoxicology and environmental safety 71:527-534

[27] Gaussian09 R.A, 1, frisch mj, trucks gw, schlegel hb, scuseria ge, robb ma, cheeseman jr,. Scalmani g, Barone v, Mennucci b, petersson ga et al. (2009), gaussian, Inc., Wallingford CT 121:150-166

[28] Dennington R, Keith T, Millam J (2009) GaussView, version 5, Semichem Inc.: Shawnee Mission, KS 
[29] Weinhold F, GlendeningE.D (2001) NBO 5.0 program manual: natural bond orbital analysis programs, Theoretical Chemistry Institute and Department of Chemistry, University of Wisconsin, Madison, WI 53706

[30] Bader R(1990).Atoms in molecule, A Quantum Theory

[31] Lee C, Yang W, Parr R.G (1988) Development of the Colle-Salvetti correlation-energy formula into a functional of the electron density, Physical review B 37:785

[32] Pascual-Ahuir J, Silla E, Tomasi J, Bonaccorsi R (1987) Electrostatic interaction of a solute with a continuum. Improved description of the cavity and of the surface cavity bound charge distribution, Journal of Computational Chemistry 8:778-787

[33] Mennucci B, Tomasi J (1997) Continuum solvation models: A new approach to the problem of solute's charge distribution and cavity boundaries, The Journal of chemical physics 106:5151-5158.

[34] Reed A.E, Curtiss L.A, Weinhold F (1988) Intermolecular interactions from a natural bond orbital, donor-acceptor viewpoint, Chemical Reviews 88:899-926

[35] Bertolasi V, Gilli P, Ferretti V, Gilli G (1991) Evidence for resonance-assisted hydrogen bonding. 2. Intercorrelation between crystal structure and spectroscopic parameters in eight intramolecularly hydrogen bonded 1, 3-diaryl-1, 3-propanedione enols, Journal of the American Chemical Society 113:4917-4925

[36] Mehrani S, Tayyari S.F, Momen Heravi M, Morsali A (2020) Vibrational spectra, normal coordinate analysis, and structure of keto form of acetylacetone. A DFT approach, Egyptian Journal of Chemistry 63:10-11

[37] Schiering D.W, Katon J (1986) The vibrational spectra and structures of dimethyl oxaloacetate and dimethyl oxaloacetate-d2, Spectrochimica Acta Part A: Molecular Spectroscopy 42:487-498.

[38] Wiberg K.B (1968) Application of the pople-santry-segal CNDO method to the cyclopropylcarbinyl and cyclobutyl cation and to bicyclobutane, Tetrahedron 24:1083-1096. .

[39] Vakili M, Tayyari S.F, Afzali R (2018). Molecular structure, spectroscopic studies, and coppereoxygen bond strength of a-methyl and a-ethyl derivatives of copper (II) acetylacetonate; Experimental and theoretical approach, Journal of Molecular Structure 1160

[40] Coussan S, Manca C, Ferro Y, Roubin P (2003) UV and IR photoisomerizations of an intramolecularly H-bonded molecule: acetylacetone trapped in nitrogen matrix, Chemical physics letters 370:118-125

[41] Coussan S, Ferro Y, Trivella A, Rajzmann M, Roubin P, Wieczorek R, Manca C, Piecuch P, Kowalski K, Włoch M (2006) Experimental and theoretical UV characterizations of acetylacetone and its isomers, The Journal of Physical Chemistry A 110:3920-3926

[42] Mohammed S.J, Salih A.K, Rashid M.A.M, Omer K.M, Abdalkarim K.A (2020) Synthesis, Spectroscopic Studies and Keto-Enol Tautomerism of Novel 1, 3, 4-Thiadiazole Derivative Containing 3-Mercaptobutan-2-one and Quinazolin-4-one Moieties, Molecules 25:5441.

[43] Sloop J.C, Bumgardner C.L, Washington G, Loehle W.D, Sankar S.S, Lewis A.B (2006) Ketoenol and enol-enol tautomerism in trifluoromethyl- $\beta$-diketones, Journal of fluorine chemistry 127:780-786.

[44] Nagashima N, Kudoh S, Takayanagi M, Nakata M (2001) UV-induced photoisomerization of acetylacetone and identification of less-stable isomers by low-temperature matrix-isolation infrared spectroscopy and density functional theory calculation, The Journal of Physical Chemistry A 105 :10832-10838

[45] Zawadiak J, Mrzyczek M (2012) Influence of substituent on UV absorption and keto-enol tautomerism equilibrium of dibenzoylmethane derivatives, Spectrochimica Acta Part A: Molecular and Biomolecular Spectroscopy 96:815-819

[46] Darugar V, Vakili M, Nekoei A, Tayyari S.F, Afzali R (2017) Tautomerism, molecular structure, intramolecular hydrogen bond, and enol-enol equilibrium of para halo substituted 4, 4, 4-trifluoro-1phenyl-1, 3-butanedione; Experimental and theoretical studies, Journal of Molecular Structure 1150:427-437

[47] Demircioğlu Z, Kaştaş Ç.A., Büyükgüngör O (2015) Theoretical analysis (NBO, NPA, Mulliken Population Method) and molecular orbital studies (hardness, chemical potential, electrophilicity and Fukui function analysis) of (E)-2-((4-hydroxy-2-methylphenylimino) methyl)-3-methoxyphenol, Journal of Molecular structure 1091:183-195 
[48] Albayrak Ç, Kaştaş G, Odabaşoğlu M, Büyükgüngör O (2011) Probing the compound (E)-2-[(4bromophenylimino) methyl]-6-ethoxyphenol mainly from the point of tautomerism in solvent media and the solid state by experimental and computational methods, Journal of Molecular Structure 1000:162-170

Table 1. Thermodynamic parameters for the most stable enol to keto tautomers of $\beta$-ketoesters and AA compounds

Table 2. The geometrical and topological parameters of the cis-enol forms of $\beta$-ketoesters and AA compounds

Table. 3. The experimental spectroscopic values related to IHB strength of the cis-enol forms and keto forms of $\beta$-ketoesters and AA compounds

Table. 4. The calculated Wiberg bond orders for average the most stable enol and keto forms for $\beta$-ketoester calculated at B3LYP/6-311++G** level

Table. 5. Selected natural atomic charges (e) for average the most stable enol and keto foems for $\beta$-ketoesters with AA

Table. 6. Relevant second order perturbation energies $\mathrm{E}^{(2)}$ (donor-acceptor) interactions of kcal.mol ${ }^{-1}$ in the most stable enol and keto forms of $\beta$-ketoester and AA compounds.

Table. 7. The experimental and B3LYP/6-311++G** calculated, wavelength $(\lambda)$, oscillator strengths $(f)$, and major contributions for stable keto and cis-enol forms of $\beta$-ketoester compounds. 
Fig. 1. Keto- Enol conformer in $\beta$-Ketoester

Fig. 2. Enolization of $\beta$-ketoester

Fig.3 The experimental UV-Vis spectra in $\mathrm{CH}_{3} \mathrm{CN}$ for $\beta$-ketoesters

Fig.4 The experimental UV-Vis spectra in Ethanol for $\beta$-ketoesters

Fig.5 The experimental UV-Vis spectra in $\mathrm{CCl}_{4}$ for $\beta$-ketoesters

Fig. 6 The HOMO and LUMO orbitals for cis-enol forms of $\beta$-ketoester and AA, HOMO $\rightarrow$ LUMO

Fig. 7 The HOMO and LUMO orbitals for keto forms of $\beta$-ketoester and AA, HOMO-n $\rightarrow$ LUMO+n 
Figures<smiles></smiles>

AU-Enol

Keto

BU-Enol

$\begin{array}{llll}\text { MAA : } & \mathrm{R}_{1}=\mathrm{CH}_{3} & \mathrm{R}_{2}=\mathrm{H} & \mathrm{R}_{3}=\mathrm{CH}_{3} \\ \text { EAA : } & \mathrm{R}_{1}=\mathrm{CH}_{3} & \mathrm{R}_{2}=\mathrm{H} & \mathrm{R}_{3}=\mathrm{C}_{2} \mathrm{H}_{5} \\ \text { EMA : } & \mathrm{R}_{1}=\mathrm{CH}_{3} & \mathrm{R}_{2}=\mathrm{CH}_{3} & \mathrm{R}_{3}=\mathrm{C}_{2} \mathrm{H}_{5} \\ \text { EBA : } & \mathrm{R}_{1}=\mathrm{Ph} & \mathrm{R}_{2}=\mathrm{H} & \mathrm{R}_{3}=\mathrm{C}_{2} \mathrm{H}_{5} \\ \text { BAA : } & \mathrm{R}_{1}=\mathrm{CH}_{3} & \mathrm{R}_{2}=\mathrm{H} & \mathrm{R} 3=\mathrm{CH}_{2} \mathrm{Ph}\end{array}$

Figure 1

Keto- Enol conformer in $\beta$-Ketoester

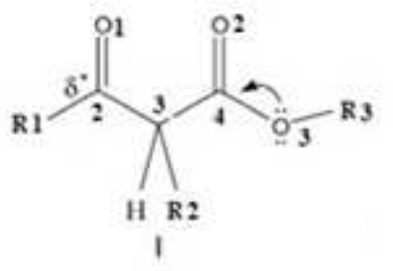<smiles>N#CC(=O)C(=O)O[Na]</smiles>

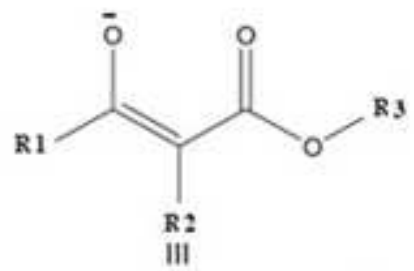<smiles>[2H]C([13O])=C([18O])O[18OH]</smiles>

Figure 2

Enolization of $\beta$-ketoester 


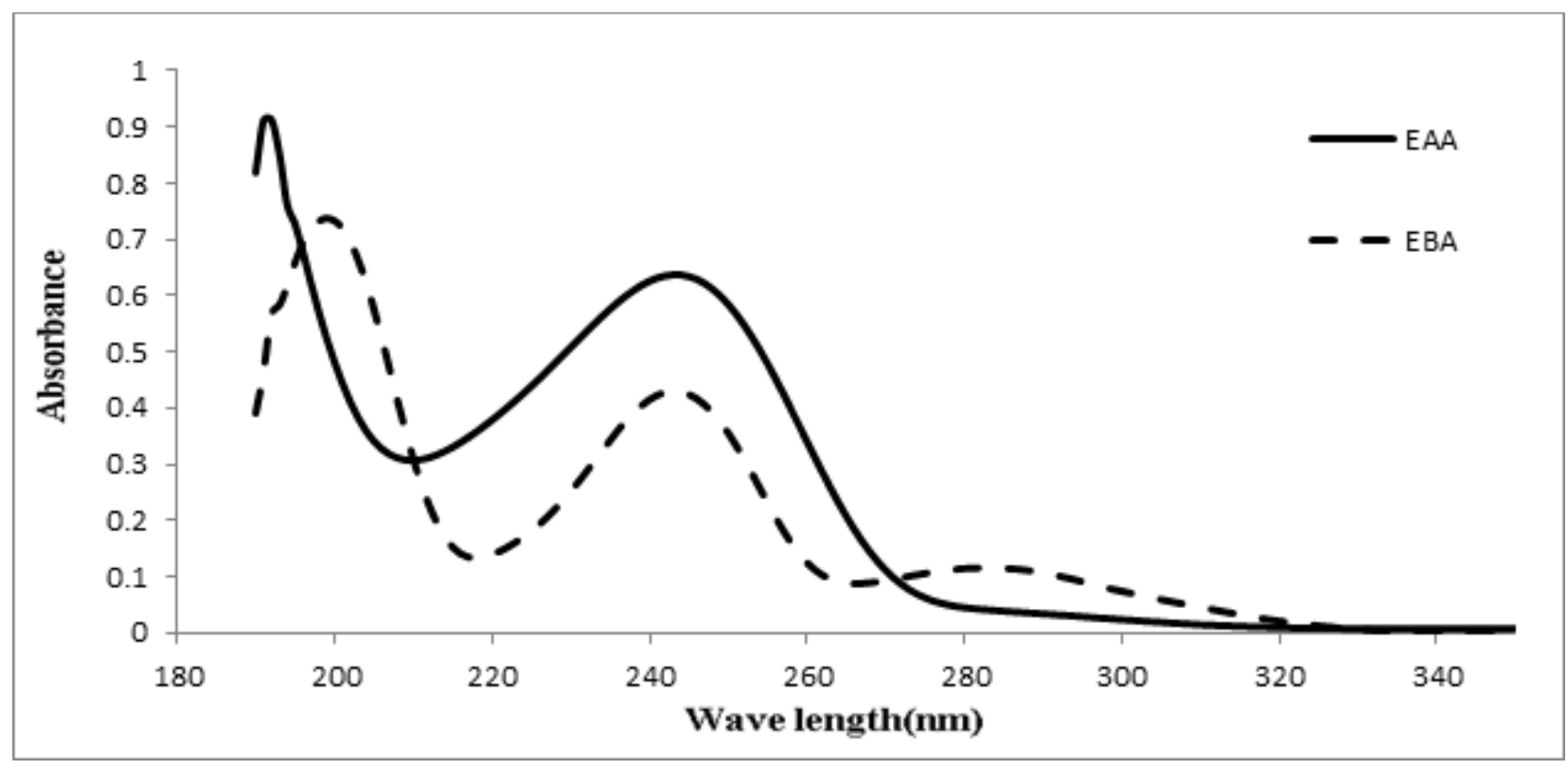

Figure 3

The experimental UV-Vis spectra in $\mathrm{CH} 3 \mathrm{CN}$ for $\beta$-ketoesters

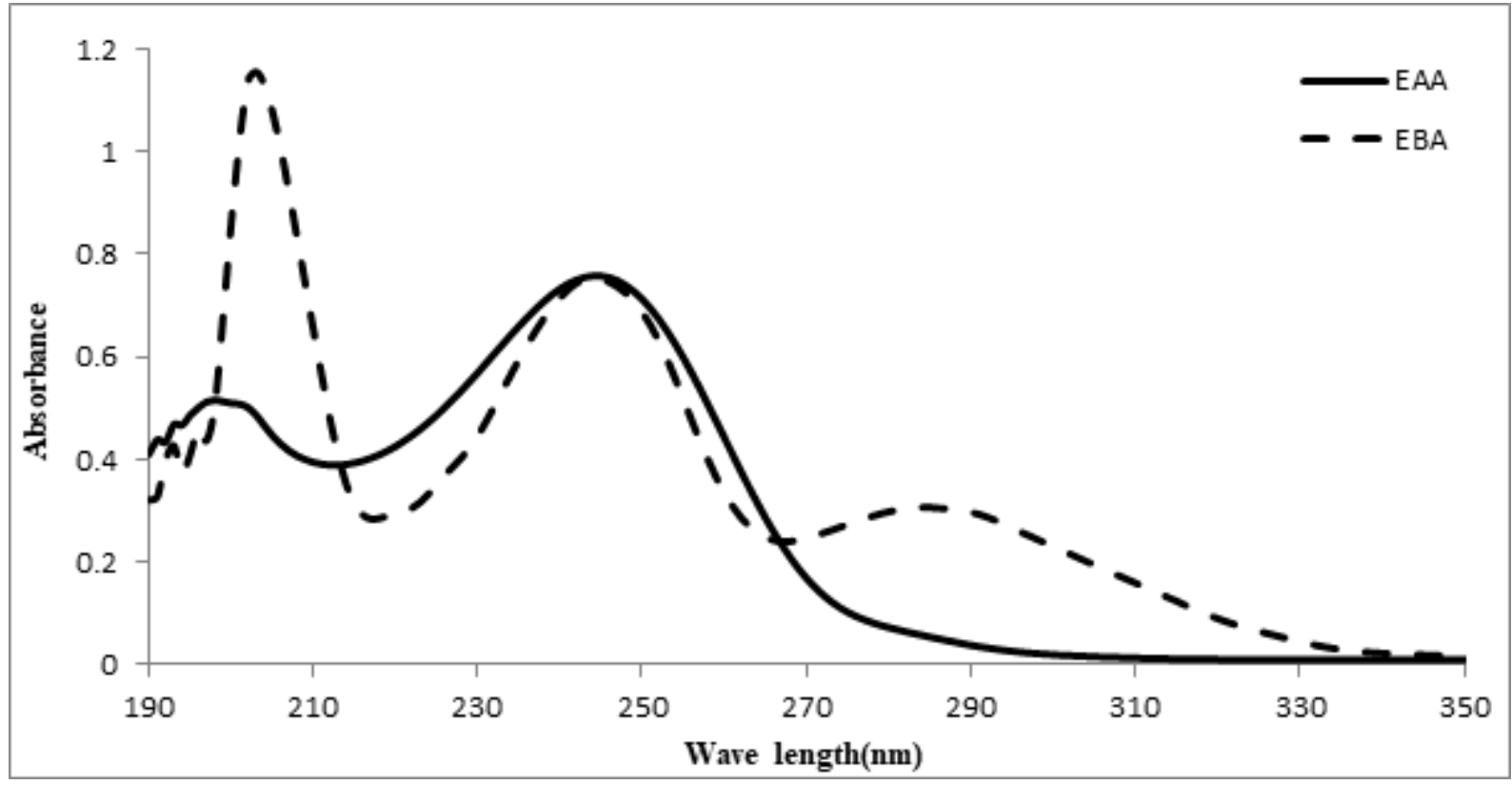

Figure 4

The experimental UV-Vis spectra in Ethanol for $\beta$-ketoesters 


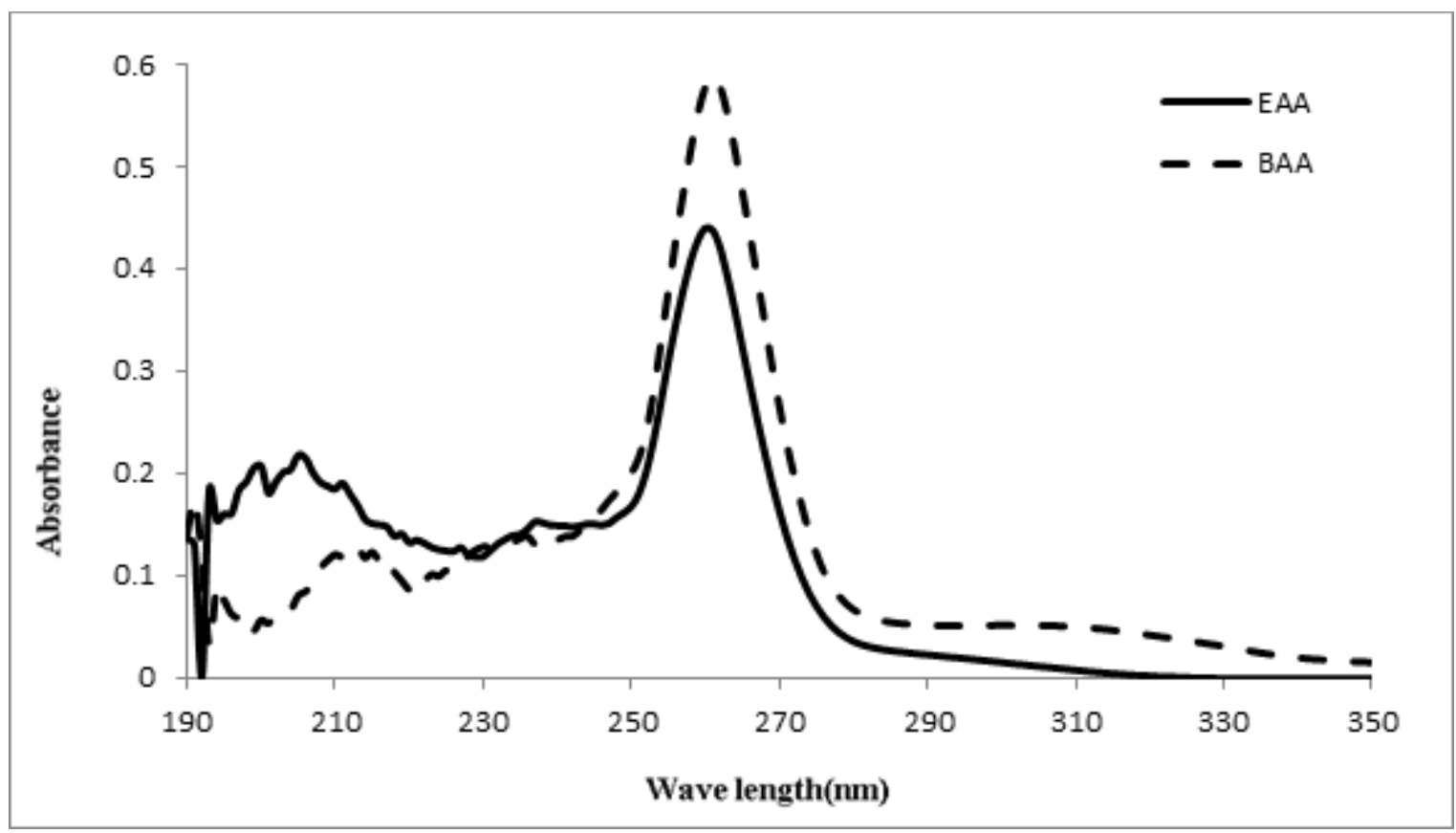

Figure 5

The experimental UV-Vis spectra in $\mathrm{CCl} 4$ for $\beta$-ketoesters
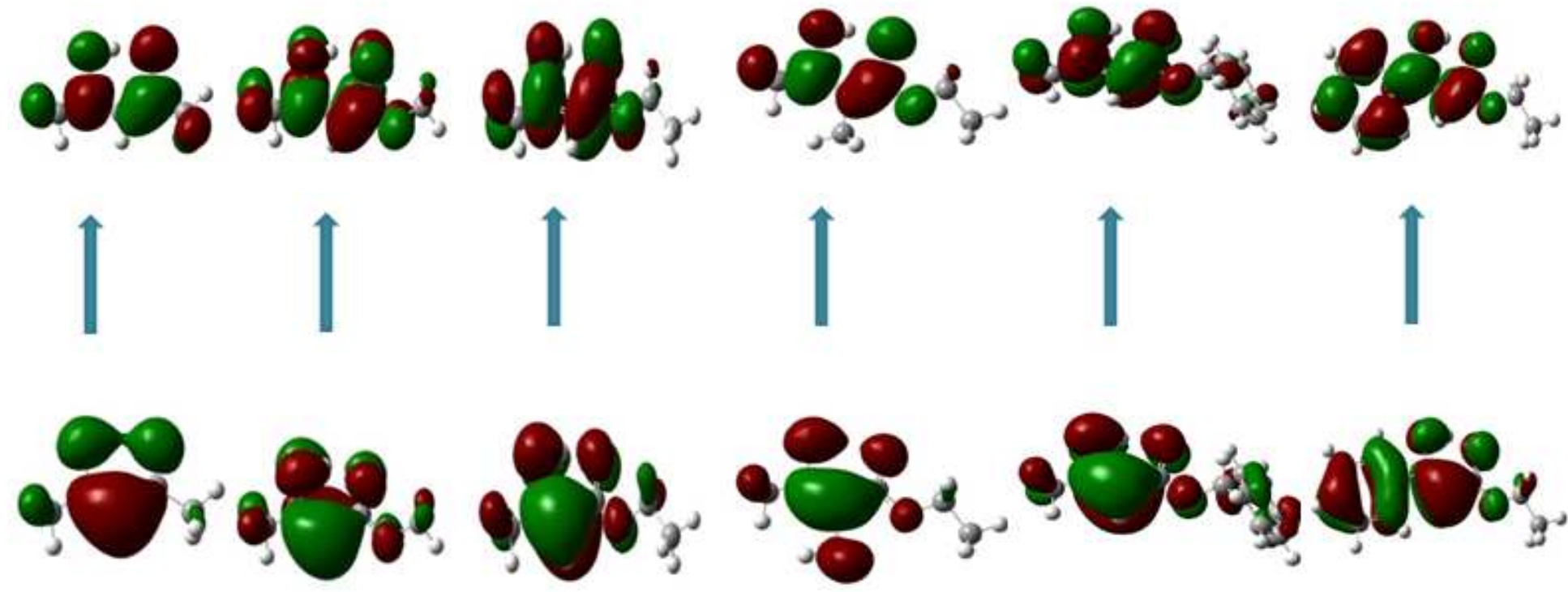

$$
\Delta \mathrm{E}=5.34 \mathrm{eV} \quad \Delta \mathrm{E}=5.69 \mathrm{eV}
$$

$\Delta \mathrm{E}=5.69 \mathrm{eV}$

$\Delta \mathrm{E}=5.39 \mathrm{eV}$

$\Delta \mathrm{E}=5.66 \mathrm{eV}$

$\Delta \mathrm{E}=4.61 \mathrm{eV}$

Figure 6

The HOMO and LUMO orbitals for cis-enol forms of $\beta$-ketoester and AA HOMO->LUMO 

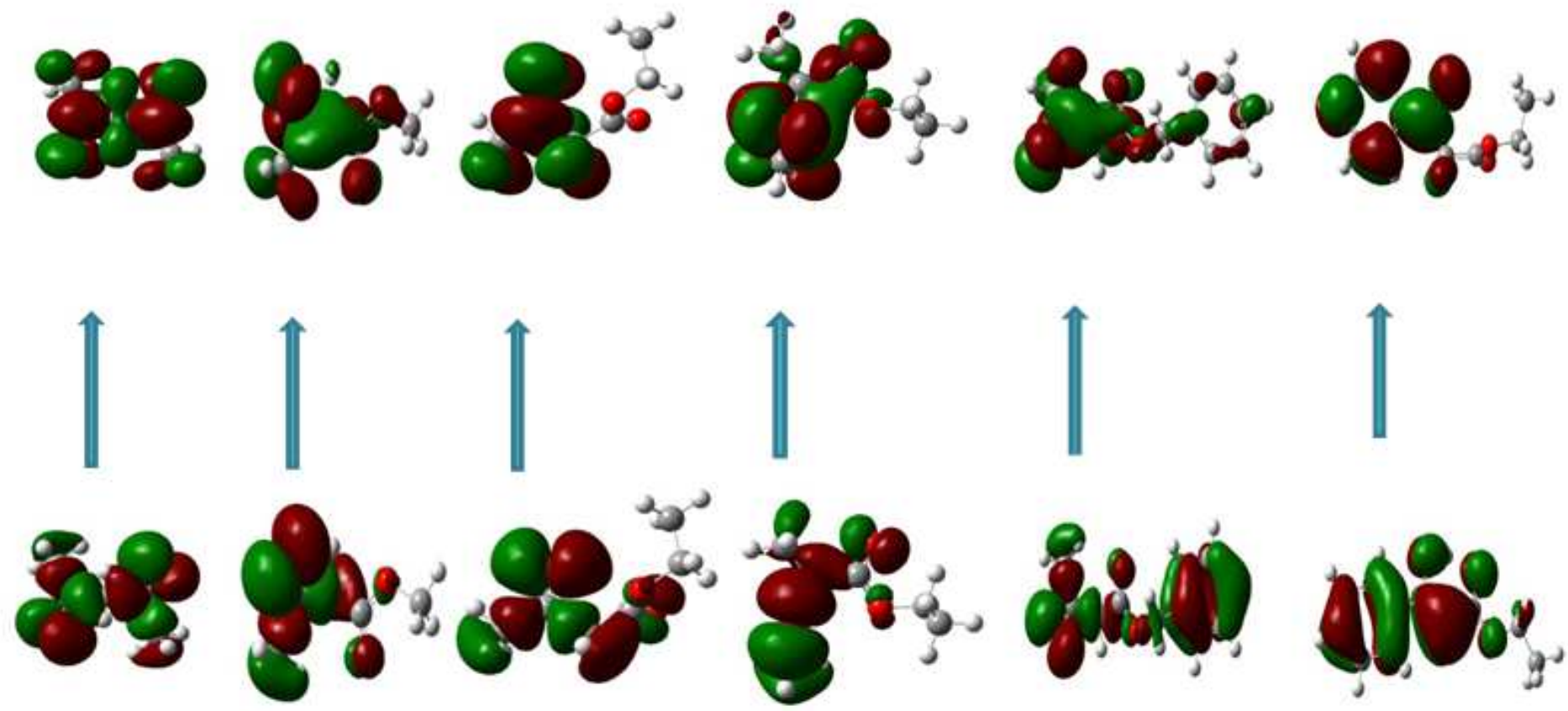

AA-Keto form MAA-Keto form EAA-Keto form

EMA-Keto form

BAA-Keto form

EBA-Keto form

$\Delta \mathrm{E}=5.57 \mathrm{eV} \quad \Delta \mathrm{E}=6.36 \mathrm{eV} \quad \Delta \mathrm{E}=6.35 \mathrm{eV}$ $\Delta \mathrm{E}=6.11 \mathrm{eV}$ $\Delta \mathrm{E}=6.11 \mathrm{eV}$ $\Delta \mathrm{E}=5.29 \mathrm{eV}$

Figure 7

The HOMO and LUMO orbitals for keto forms of $\beta$-ketoester and AA HOMO-n->LUMO+n

\section{Supplementary Files}

This is a list of supplementary files associated with this preprint. Click to download.

- supplimental.docx 